\title{
Hematopoietic Origin of Murine Lung Fibroblasts
}

\author{
Lindsay T. McDonald, ${ }^{1,2}$ Meenal Mehrotra, ${ }^{2}$ and Amanda C. LaRue ${ }^{1,2,3}$ \\ ${ }^{1}$ Research Services, Ralph H. Johnson Department of Veterans Affairs Medical Center, Charleston, SC 29401, USA \\ ${ }^{2}$ Department of Pathology and Laboratory Medicine, Medical University of South Carolina, Charleston, SC 29425, USA \\ ${ }^{3}$ Hollings Cancer Center, Medical University of South Carolina, Charleston, SC 29425, USA
}

Correspondence should be addressed to Amanda C. LaRue; laruerc@musc.edu

Received 14 February 2015; Revised 21 May 2015; Accepted 25 May 2015

Academic Editor: Renke Li

Copyright (C) 2015 Lindsay T. McDonald et al. This is an open access article distributed under the Creative Commons Attribution License, which permits unrestricted use, distribution, and reproduction in any medium, provided the original work is properly cited.

\begin{abstract}
Multiple origins, including the bone marrow, have been suggested to contribute to fibroblast populations in the lung. Using bone marrow reconstitution strategies, the present study tested the hypothesis that the bone marrow hematopoietic stem cell (HSC) gives rise to lung tissue fibroblasts in vivo. Data demonstrate that the nonadherent bone marrow fraction is enriched for CD45 HSC-derived cells and was able to reconstitute hematopoiesis in lethally irradiated animals. Analysis of peripheral blood and lung tissues from engrafted mice demonstrated the ability of this population to give rise to CD $45^{+} /$Discoidin-Domain Receptor- $2^{+}$ (DDR2) circulating fibroblast precursors (CFPs) in blood and fibroblast populations in lung. An HSC origin for lung fibroblasts was confirmed using a novel clonal cell transplantation method in which the bone marrow is reconstituted by a clonal population derived from a single HSC. Together, these findings provide evidence for an HSC contribution to lung fibroblasts and demonstrate a circulating intermediate through the $\mathrm{CD} 45^{+} / \mathrm{DDR} 2^{+}$HSC-derived CFP.
\end{abstract}

\section{Introduction}

Several studies have suggested a bone marrow origin for a subpopulation of lung fibroblasts $[1,2]$; however the stem cell in the bone marrow that gives rise to this population remains unclear. Fibrocytes, circulating cells with the potential to differentiate into mature fibroblasts [3], have been identified in many tissues including lung [4]. These cells have been shown to express hematopoietic markers including CD45 and CD34, suggesting an origin from the hematopoietic stem cell (HSC); however, their mesenchymal nature has brought into light the possibility that the origin of this population may be through the mesenchymal stem cell (MSC). Examination of lung fibroblasts in pulmonary disease such as pulmonary fibrosis has led some to question whether proliferation of the resident lung population alone could explain the relative prominence and heterogeneity of fibroblasts found in the fibrotic foci that characterize this disease (reviewed in [5]). In support of an extrapulmonary origin of lung fibroblasts and myofibroblasts, studies have shown multiple sources of fibroblasts including an MSC origin [6], an origin through epithelial to mesenchymal transformation (EMT) (reviewed in [7]), endothelial to mesenchymal transformation (endoMT) [8], or through resident fibroblast contribution ([9] and reviewed in [10]). However, to our knowledge, to date, there have been no direct lineage tracing studies addressing the origin of lung fibroblast populations. These studies have resulted in several key unanswered questions in the study of lung pathophysiology including the following: What is the origin of lung fibroblasts? What is the bone marrow progenitor population that gives rise to these cells? And what is the phenotype and functional role of the recruited cells based on origin in both normal and disease states? (reviewed in [5]). Investigating these questions has the potential to uncover hitherto underappreciated differences and similarities between pulmonary fibroblasts of multiple origins as well as to inform research directed at elucidating the differentiation and maturation pathways of these populations towards the ultimate goal of impacting human health and disease.

Recent studies by our laboratory (reviewed in [11, 12]) and others (reviewed in [13]) have demonstrated greater plasticity of bone marrow HSCs than previously appreciated. 
Through direct lineage tracing studies, using a unique clonal cell transplantation method in which a clonal population derived from a single $\mathrm{EGFP}^{+}$HSC is transplanted into lethally irradiated mice, our laboratory has demonstrated an HSC origin for a number of mesenchymal cell types including adipocytes, chondrocytes, osteoblasts/osteocytes, and fibroblasts (reviewed in [11]). In particular, our laboratory has previously demonstrated that HSCs give rise, through a nonfusion mechanism [14-18], to bone marrow colony forming unit fibroblasts (CFU-F) [19], circulating fibrocytes/fibroblast precursors $[19,20]$, and fibrocytes in the inner ear [16], as well as mature tissue fibroblasts including cancer-associated fibroblasts $([20,21]$ and reviewed in $[22,23])$, glomerular mesangial cells of the kidney [18], and fibroblasts in the valves of the heart [15].

In the present study, we sought to determine the potential of the HSC to give rise to mature lung fibroblasts and monitor the transition of these cells through the peripheral blood to their incorporation into the lung as tissue fibroblasts. Our findings demonstrated that the nonadherent fraction of bone marrow was enriched for HSC-derived cells and this population gave rise to multilineage hematopoietic engraftment. Further, we showed that the peripheral blood of wild-type mice engrafted with the nonadherent bone marrow fraction from enhanced green fluorescent protein (EGFP) mice contains $\mathrm{EGFP}^{+}$circulating fibroblast precursors (CFPs). In addition, the lungs of engrafted mice were shown to contain $\mathrm{EGFP}^{+}$CFPs as well as $\mathrm{EGFP}^{+}$Collagen I expressing cells with a fibroblastic morphology, suggesting that nonadherent bone marrow derived circulating fibroblast precursors gave rise to mature lung fibroblasts in vivo. As confirmation of the HSC origin of the lung fibroblast, analysis of the lungs of clonally engrafted mice also demonstrated the presence of these cells. Thus, studies herein demonstrate that a population of lung fibroblasts is derived from the HSC in nondisease state.

\section{Methods}

2.1. Mice. C57Bl/6/CD45.1 breeders were from Jackson Laboratories. EGFP breeders (C57Bl/6/CD45.2 background) were provided by Dr. M. Okabe (Osaka University, Japan) [24]. Mice were bred and maintained in the Animal Research Facility, VAMC. Research was conducted in accordance with guidelines set by the US Public Health Service Policy on Humane Care and Use of Laboratory Animals and the VAMC IACUC.

2.2. Antibodies. Fluorochrome-conjugated, biotinylated, or purified versions of the following antibodies were used: anti-CD45R/B220 (RA3-6B2), anti-Gr-1 (anti-Ly-6G[RB68C5]), anti-Macl (anti-CD11b[M1/70]), anti-Thy-1.2 (30H12), anti-CD45 (Leukocyte Common Antigen, Ly-5;30F11), anti-CD45.1 (A20) from BD Biosciences; anti-DDR2 (anti-Discoidin Domain Receptor-2) (N-20) from SantaCruz; anti-collagen-I (ab21286), anti-CD45 (ab10558), antiGFP (ab13970) from Abcam; isotype control antibodies from BD Biosciences/Pharmingen or Santa Cruz; all secondary antibodies from Jackson ImmunoResearch.

\subsection{Bone Marrow Isolation and Nonadherent Bone Marrow} Transplantation. Total bone marrow was harvested by flushing femurs and tibiae of C57Bl/6-EGFP/CD45.2 mice. For generation of nonadherent bone marrow, mononuclear cells were isolated using Lympholyte $\mathrm{M}$ (Cedar Lane) and differential centrifugation. Cells were washed in $0.1 \%$ BSA/PBS and were plated in $\alpha \mathrm{MEM}$ containing 20\% FBS and supplemented with $1 \%$ Penicillin/Streptomycin. Approximately 96 hours after isolation the nonadherent population was removed and cells were then washed and resuspended in PBS $\left(2 \times 10^{6}\right.$ cells $\left./ 100 \mu \mathrm{L}\right)$ and injected by tail vein into lethally irradiated $\mathrm{C} 57 \mathrm{Bl} / 6 / \mathrm{CD} 45.1$ recipient mice (totalbody irradiation, 850 cGy). Mice were euthanized 10-12 weeks after transplant. Total $\mathrm{EGFP}^{+} / \mathrm{CD} 45.1^{-}$engraftment and multilineage engraftment of $\mathrm{EGFP}^{+}$cells in the B cell, $T$ cell, and granulocyte/macrophage lineages were confirmed (Table 1). For flow cytometric quantification of total engraftment, isotype controls were used to set gates for CD45.1 and EGFP populations of sized, propidium iodide negative (live) cells. In order to determine multilineage engraftment, analysis of flow cytometric data was as follows: sized, live cells were selected and gates were set on the B cell, T cell, or granulocyte/macrophage populations against isotype controls. Expression of EGFP was then analyzed from these gated populations in order to determine the percentage of EGFP expressing cells in each of the blood lineages.

2.4. Clonal Cell Transplantation. Clonal cell transplantation was performed as previously described [19-21, 25]. Briefly, lineage negative $\left(\mathrm{Lin}^{-}\right)$cells were isolated from bone marrow of 10-14-week-old C57Bl/6-EGFP/CD45.2 mice by negative selection following staining and DynaBead removal of B220, Gr-1, CD4, CD8a, and TER-119 positive cells. Lin ${ }^{-}$cells were stained with antibodies to Sca-1, c-kit, and CD34. Single Lin ${ }^{-} \mathrm{Sca}-1^{+} \mathrm{ckit}^{\text {hi }} \mathrm{CD} 34^{-}$cells were deposited into individual wells of 96-well culture plates (MoFlo CyCLONE system). Eighteen hours after deposition, wells containing single cells were identified and cultured for 7 days in $\alpha$-modification of Eagle's medium ( $\alpha$ MEM, Life Technologies), 20\% fetal bovine serum (FBS, Atlanta Biologicals), 10\% bovine serum albumin (BSA, Life Technologies), $1 \times 10^{-2} \mathrm{~mol} / \mathrm{L} 2$-mercaptoethanol (Sigma), $10 \mu \mathrm{g} / \mathrm{mL}$ stem cell factor (SCF), and $10 \mu \mathrm{g} / \mathrm{mL}$ interleukin-11 (IL-11, R\&D Systems). Wells containing $\leq 20$ clonal cells were selected for transplantation. Recipient C57Bl/6/CD45.1 mice were lethally irradiated (total-body irradiation, $950 \mathrm{cGy}$ ). Clonal cells were injected intravenously with $500 \mathrm{CD} 45.1 / \mathrm{EGFP}^{-} / \mathrm{Lin}^{-} \mathrm{ckit}^{+} \mathrm{Sca}-1^{+} \mathrm{CD} 4^{+}$radioprotective cells. Radioprotective cells are sorted EGFP negative cells that are used as short-term repopulating cells to allow the animals to survive the postirradiation pancytopenia period prior to engraftment [26]. Mice were euthanized up to one year after clonal cell transplantation. Total $\mathrm{EGFP}^{+} / \mathrm{CD} 45.1^{-}$ engraftment and multilineage engraftment of EGFP cells in the B cell, T cell, and granulocyte/macrophage lineages was confirmed (Table 3). Flow cytometric quantification of total and multilineage engraftment was performed as described above. 
TABLE 1: Nonadherent fraction bone marrow transplantation results in multilineage hematopoietic engraftment.

\begin{tabular}{lcccc}
\hline & $\begin{array}{c}\text { Total engraftment } \\
\left(\% C D 45.1^{-} / \mathrm{EGFP}^{+}\right)\end{array}$ & $\begin{array}{c}\text { B cell engraftment } \\
\left(\% B 220^{+} / \mathrm{EGFP}^{+}\right)\end{array}$ & $\begin{array}{c}\text { T cell engraftment } \\
\left(\% \text { Thy1.2 } / \mathrm{EGFP}^{+}\right)\end{array}$ & $\begin{array}{c}\text { Granulocyte/macrophage engraftment } \\
\left(\% \mathrm{Grl}_{\mathrm{Mac1}} / \mathrm{EGFP}^{+}\right)\end{array}$ \\
\hline M1 & 80.8 & 81.7 & 36.1 & 81.4 \\
M2 & 87.6 & 82.5 & 36.5 & 85.9 \\
M3 & 85.7 & 90.6 & 44.4 & 84.6 \\
M4 & 55.2 & 60.0 & 22.9 & 60.0 \\
M5 & 84.4 & 80.5 & 41.4 & 81.5 \\
\hline
\end{tabular}

M1-M5 represent five individual mice transplanted with $\mathrm{EGFP}^{+}$nonadherent bone marrow. As we have previously noted, the low level T cell engraftment reflects slow turnover of $\mathrm{T}$ cells in vivo.

2.5. Immunofluorescence. Lungs were harvested from engrafted animals and samples were fixed in zinc fixative (BD Biosciences) or $4 \%$ paraformaldehyde (Affymetrix). Tissues were paraffin embedded and $5 \mu \mathrm{M}$ sections cut. Citrate buffer (Vector Laboratories) mediated antigen retrieval was performed on lung tissue sections. Tissues were permeabilized in $0.02 \%$ Triton X-100/PBS, 5\% serum blocked, incubated with primary antibodies listed above, and used at the following concentrations: anti-GFP 1:500, anti-Collagen I 1:50, anti-CD45 (ab10558) 1:100, and antiDDR2 1:50. Samples were washed in PBS before incubation with fluorochrome-conjugated secondary antibodies used at 1:100 concentration in 5\% serum. Hoechst 33342 was used as a nuclear marker. Sections were gel mounted (Electron Microscopy Sciences) and coverslipped for imaging.

2.6. Microscopy and Quantitative Analysis. Imaging was performed using a Nikon AlR confocal system and images were processed using NIS Elements (Nikon) and Adobe Photoshop CS5 (Adobe Systems). Fluorescent and differential interference contrast (DIC) images of lung sections from transplanted mice were taken at $400 \mathrm{x}$ and $600 \mathrm{x}$ magnification. For quantification, 2 sections with a minimum of 4 sections between were imaged at $400 \mathrm{x}$ for each mouse and 2 fields per section were quantified ( $n=3$ for nonadherent transplant mice and $n=2$ for clonal cell transplant mice). Quantification of each cell population was expressed as a percent with ranges in tables. Images were shown at 600x magnification; Supplemental Figure S1 in Supplementary Material available online at http://dx.doi.org/10.1155/2015/159713 was shown at 400x magnification.

2.7. Flow Cytometry. Cells were resuspended in PBS and were blocked in 10\% donkey serum (Jackson ImmunoResearch) for 20 minutes or were stained without block. Antibodies to cell surface proteins were added for 15 minutes at $4^{\circ} \mathrm{C}$ in the dark. Cells were washed and resuspended in PBS and propidium iodide was added immediately before assay on a FACs Calibur Cytometer (BD Biosciences). Isotype controls were used to set gates. Data was analyzed using FlowJo v7.6.5 and v10 (TreeStar Inc.).

2.8. Statistics. Analysis was conducted using Microsoft Excel. Data were presented as the mean \pm standard deviation where appropriate. Student's $t$-test was used to compare groups. $P \leq$ 0.05 was regarded as statistically significant.

\section{Results}

3.1. Nonadherence Enriched for CD45 Expressing Cells. Hematopoietic stem cells (HSCs) are immature cells that reside in the bone marrow and that possess the ability to give rise to colony forming cells and are capable of hematopoietic reconstitution [27-29]. These are distinct from bone marrow mesenchymal stem cells (MSCs) which are generally isolated and identified by their ability to adhere to plastic in vitro [30] and are characterized by their lack of expression of hematopoietic markers, including CD45 [31], the panleukocyte hematopoietic marker. In order to demonstrate that isolation based on nonadherence is enriched for the hematopoietic derived population, total bone marrow was first isolated from wild-type mice and analyzed for the expression of CD 45 by flow cytometry. Approximately $68.4 \% \pm$ SD $5.9 \%$ of the total, live, bone marrow population expressed CD45 (Figure 1). Total bone marrow was then plated on tissue culture treated flasks for 96 hours to allow for adherence. The nonadherent fraction was then removed and analyzed for expression of CD45 by flow cytometry. Quantification demonstrated that $93.4 \% \pm$ SD $0.3 \%$ of the nonadherent fraction expressed CD45. This shows that the nonadherent bone marrow fraction obtained after 96 hours of adherence culture was significantly enriched for CD45 as compared to the total bone marrow population $(93.4 \% \pm$ SD $0.3 \%$ versus $68.4 \% \pm$ SD $5.9 \%$, resp.; $\left.{ }^{*} P=0.002\right)$, indicating significant enrichment for the HSC-derived population (Figure 1).

\subsection{Nonadherent Bone Marrow Transplantation Gives Rise} to Multilineage Hematopoietic Engraftment. Mice were transplanted with bone marrow after 96 hours of selection for the nonadherent [32,33], CD45 enriched fraction. Recipient CD45.1 mice were analyzed for total engraftment by flow cytometry 10 weeks after transplantation. High level engraftment $(>50 \%)$ of $\mathrm{CD} 45.1^{-} / \mathrm{EGFP}^{+}$nucleated peripheral blood cells was confirmed. Total engraftment from a representative animal is depicted (Figure 2(a)). One characteristic of hematopoietic stem cells is in their capacity to repopulate all blood lineages. Therefore, as additional confirmation of enrichment of the nonadherent bone marrow fraction for HSCs [27, 29, 32-34], multilineage engraftment was confirmed in transplanted mice by flow cytometric analysis. Analysis revealed high level engraftment of $\mathrm{EGFP}^{+}$cells in each of the blood lineages including the B cell $\left(\mathrm{B}_{220^{+}}\right)$, 


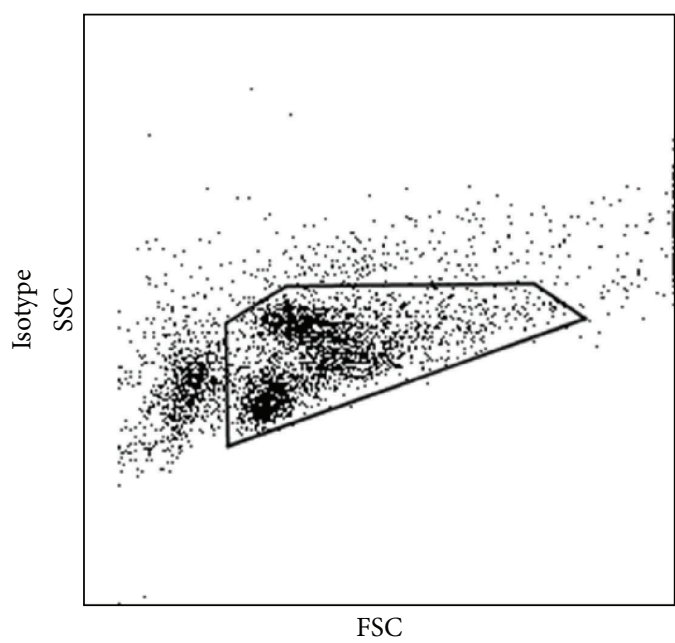

(a)

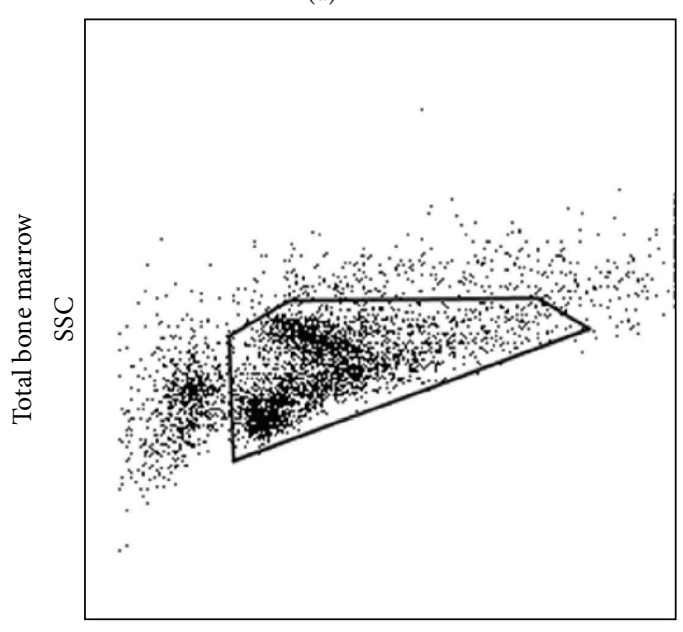

FSC

(c)

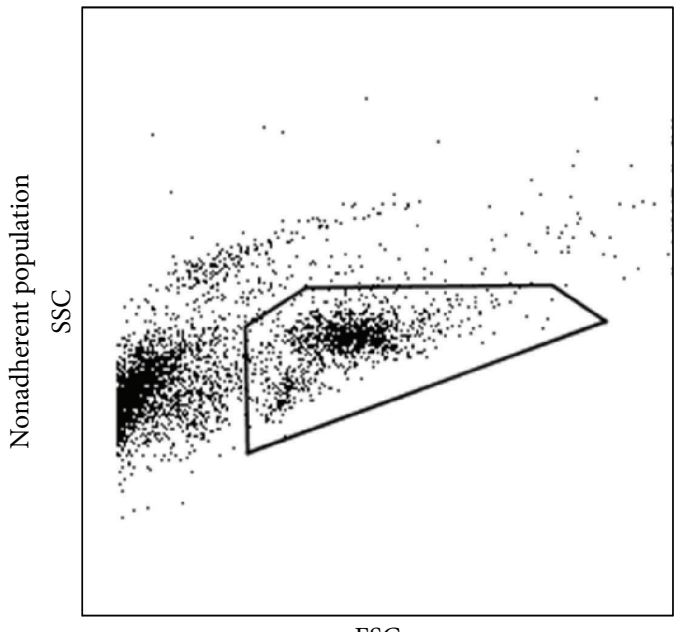

(e)

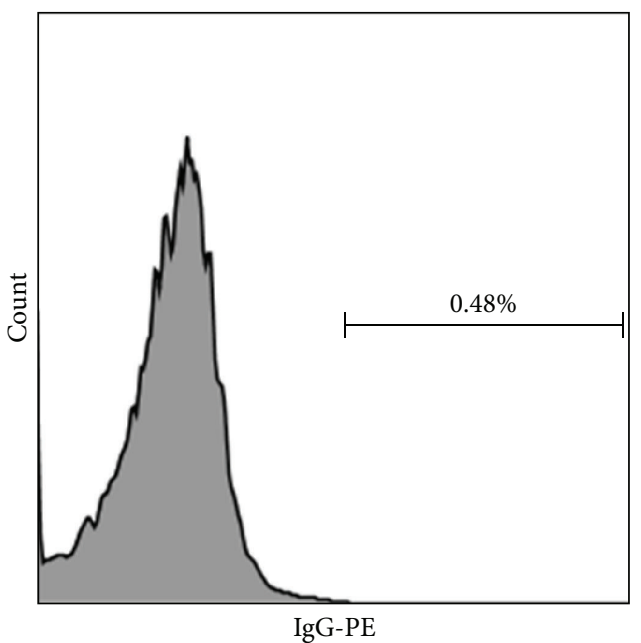

(b)

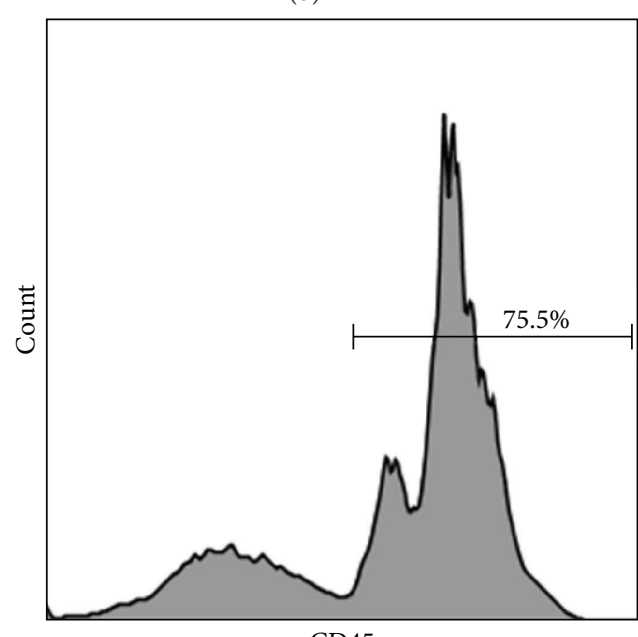

(d)

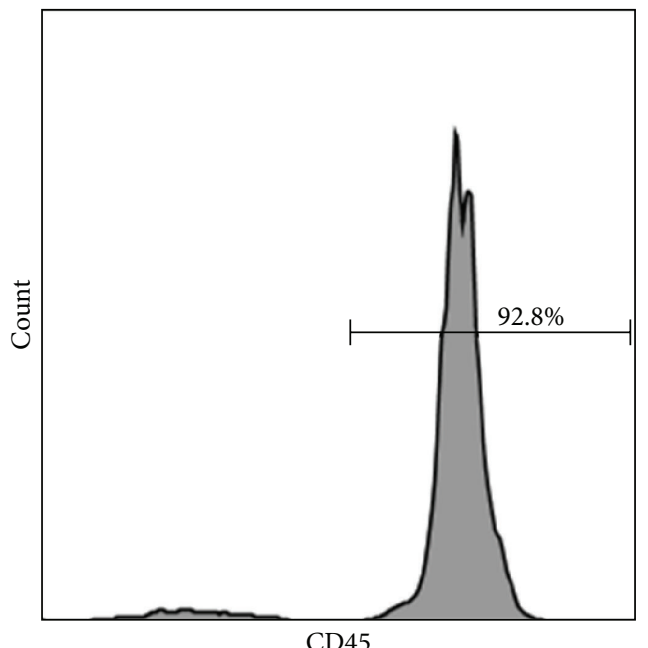

(f)

FIGURE 1: Adherence culture enriched for the HSC-derived population in the nonadherent fraction of bone marrow. Flow cytometric analysis of CD45 expression in total bone marrow was compared to that in the 96-hour nonadherent bone marrow population. A representative analysis is shown. Panel (a) shows forward and side scatter gate and Panel (b) shows isotype control for CD45 staining gated on the live, propidium iodide (PI) negative population. A representative analysis of CD45 expression by total bone marrow is shown where Panel (c) depicts the forward and side scatter gate and Panel (d) shows CD45 staining gated on the live, PI negative population. Panel (e) depicts the forward scatter and side scatter gate for the nonadherent bone marrow fraction, and Panel (f) shows the CD45 staining gated on the live, PI negative population. 


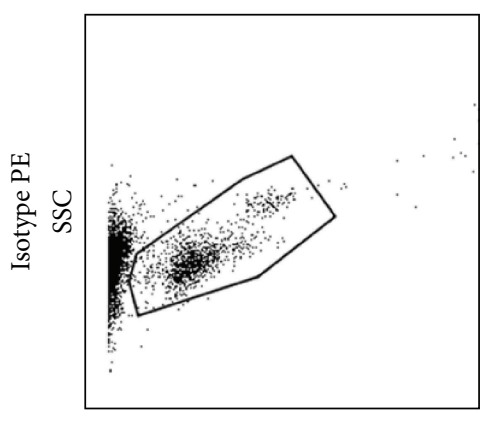

FSC

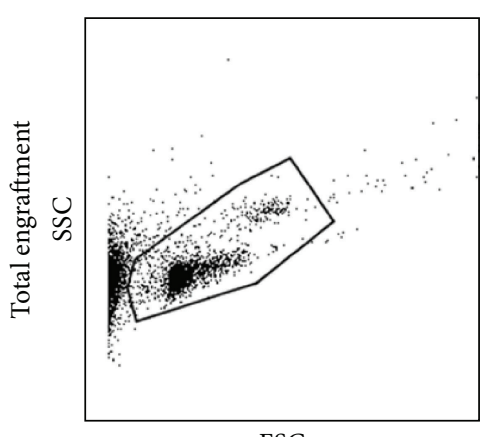

FSC
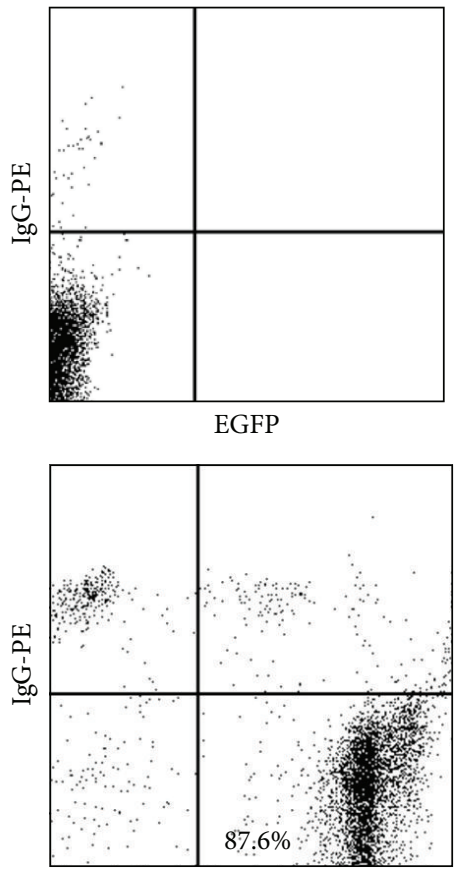

EGFP

(a)

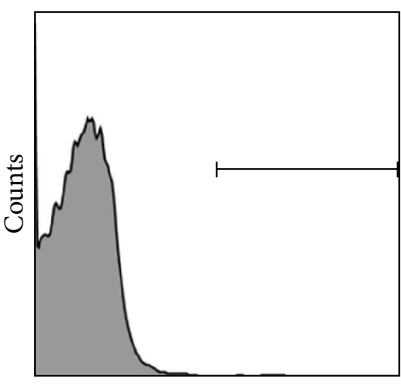

IgG-PE

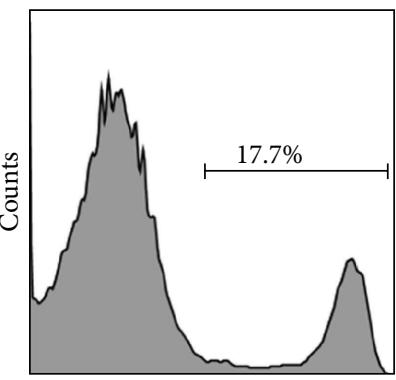

Thy1.2-PE

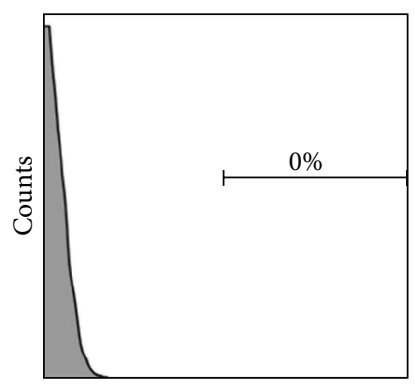

EGFP

(i)

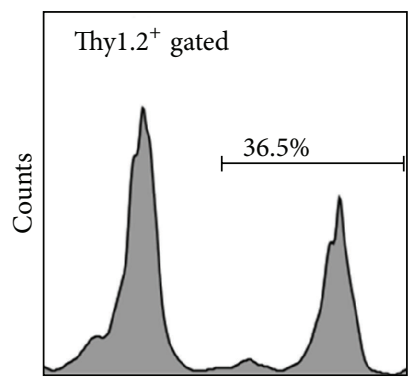

EGFP

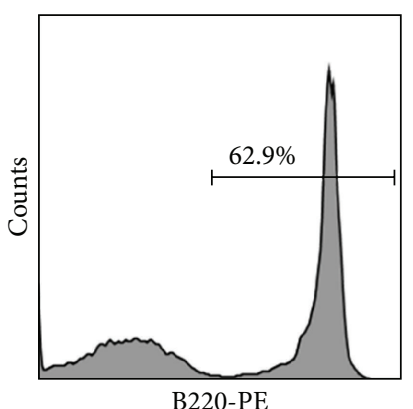

B220-PE

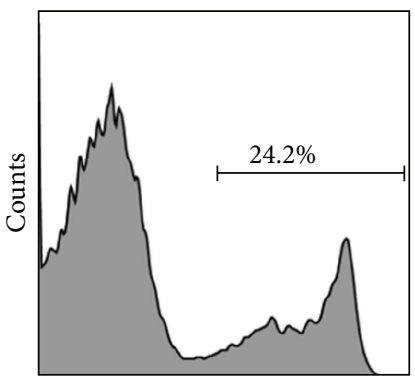

Gr1/Mac1-PE

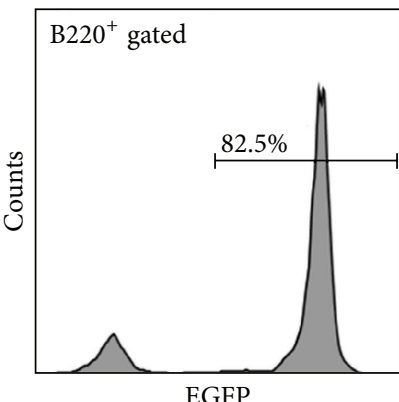

(ii)

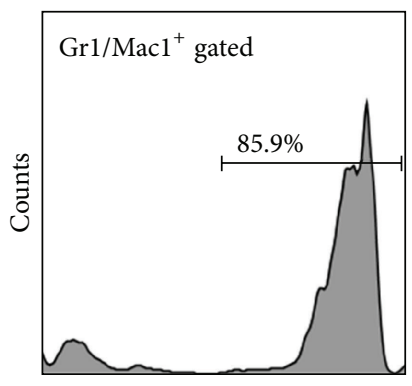

EGFP

(iii)

(iv)

(b)

FIGURE 2: Transplantation of nonadherent bone marrow results in multilineage hematopoietic engraftment. Shown is a representative analysis of total (a) and multilineage (b) engraftment approximately 2 months after transplantation of nonadherent bone marrow cells. Isotype (top panels) forward scatter and side scatter gate is shown (left) with IgG-PE versus EGFP gate (right). Representative total engraftment is shown in Panel (a) (bottom panels) with forward scatter and side scatter gate (left) and PE and EGFP gates shown (right). (b) Representative multilineage engraftment analysis is depicted in Panel (b). The isotype IgG PE gate and the EGFP population gated on the IgG PE population are depicted in (i). Analysis of B cell (ii), T cell (iii), and granulocyte/macrophage (iv) populations demonstrates EGFP ${ }^{+}$cells representing $82.5 \%, 36.5 \%$, and $85.9 \%$ of each lineage, respectively. In all dot plots (i-iv), total populations are shown on the left, and EGFP ${ }^{+}$cells within the gated population are shown on the right. See Table 1 for engraftment for all mice. 
TABLE 2: Heterogeneity of EGFP cells in lungs of transplanted animals.

\begin{tabular}{lccccc}
\hline & EGFP & EGFP & EGFP & EGFP & $\begin{array}{c}\text { EGFP } \\
\text { Col I }\end{array}$ \\
Col I/DDR2 & CD45/DDR2 & $3.4 \%$ & $14.1 \%$ & $16.9 \%$ \\
$\begin{array}{l}\text { Nonadherent } \\
\text { transplant }\end{array}$ & $25.0 \%$ & $8.6 \%$ & $(0 \%-6.4 \%)$ & $(4.2 \%-40.0 \%)$ & $(6.4 \%-26.8 \%)$ \\
\hline
\end{tabular}

Average percentage in each phenotype is indicated in top row. Bottom row gives range of percentages of each phenotype.

TABLE 3: Total and multilineage hematopoietic engraftment from a clonal population derived from a single $\mathrm{EGFP}^{+} \mathrm{HSC}_{\text {. }}$

\begin{tabular}{ccccc}
\hline & $\begin{array}{c}\text { Total engraftment } \\
\left(\% \mathrm{CD} 45.1^{-} / \mathrm{EGFP}^{+}\right)\end{array}$ & $\begin{array}{c}\text { B cell engraftment } \\
\left(\% \mathrm{~B} 220^{+} / \mathrm{EGFP}^{+}\right)\end{array}$ & $\begin{array}{c}\text { T cell engraftment } \\
\left(\% \text { Thyl.2 } / \mathrm{EGFP}^{+}\right)\end{array}$ & $\begin{array}{c}\text { Granulocyte/macrophage engraftment } \\
\left(\% \mathrm{Grl}^{+} / \mathrm{Macl}^{+} / \mathrm{EGFP}^{+}\right)\end{array}$ \\
\hline M1 & 55.1 & 76.2 & 28.3 & 87.9 \\
M2 & 93.6 & 98.5 & 62.4 & 99.8 \\
\hline
\end{tabular}

M1 and M2 represent two animals transplanted with a clonal population derived from a single sorted $\mathrm{EGFP}^{+} \mathrm{HSC}_{\text {. }}$

T cell (Thyl. $\left.2^{+}\right)$, and granulocyte/macrophage $\left(\mathrm{Grl}^{+} / \mathrm{Macl}^{+}\right)$ populations of nucleated peripheral blood cells at 10 weeks after transplant. Multilineage engraftment from a representative animal is shown (Figure 2(b)). Total and multilineage engraftment of each of the animals used herein is included in Table 1.

3.3. Circulating Fibroblast Precursors (CFPs) Arise from the Nonadherent Bone Marrow Fraction. Our laboratory has previously identified an HSC-derived circulating fibroblast precursor (CFP) in the peripheral blood of mice transplanted with a clonal population of cells derived from a single HSC [20]. CFPs were defined by the coexpression of CD45 and Discoidin Domain Receptor-2 (DDR2) [20] and were shown to give rise to mature fibroblasts in vitro and tissues in vivo [20]. Therefore, in the present study we sought to determine whether the nonadherent bone marrow fraction could give rise to $\mathrm{CD} 45^{+} / \mathrm{DDR} 2^{+}$CFPs in the peripheral blood in vivo. Flow cytometric analysis of nucleated peripheral blood cells of engrafted mice revealed $93.3 \% \pm$ SD $2.5 \%$ of $\mathrm{CD}_{4} 5^{+} / \mathrm{DDR} 2^{+}$cells coexpressed EGFP (Figure 3 ). Our previous studies using clonal cell transplantation indicated that $\sim 99 \%$ of these $\mathrm{CD} 45^{+} / \mathrm{DDR} 2^{+}$cells were derived from the HSC [20]. This data further supports the enrichment of the nonadherent bone marrow fraction for HSC-derived cells and identifies a bone marrow HSC origin of CFPs in the peripheral blood.

3.4. CFPs Are Present in the Lungs of Nonadherent Transplant Mice. In order to determine whether these CFPs were present in the lung, tissue sections obtained from the lungs of highly engrafted, nonadherent bone marrow transplanted mice were immunostained for fibroblast precursor markers (CD45/DDR2). Quantitative analysis of EGFP expression showed that $20.1 \%$ of cells within the lung tissue were EGFP ${ }^{+}$, indicating their origin from the nonadherent CD45 enriched bone marrow fraction (Figure 4, quantified in Table 2). Colocalization analysis showed expression of EGFP, CD45, and DDR2 by a subset of cells (8.59\% quantitated in Table 2; representative cell indicated by ${ }^{*}$ in Figure 4$)$. Cells were also identified which expressed CD45 and DDR2 (arrow) but were $\mathrm{EGFP}^{-}$indicating cells that either arrived prior to bone marrow transplant or were from an alternative source.

3.5. Nonadherent Bone Marrow Transplant Results in Multiple EGFP $^{+}$Fibroblastic Populations in Lung. In order to determine whether nonadherent bone marrow could give rise to mature lung fibroblasts, lung tissue sections from engrafted nonadherent transplant mice were immunostained for EGFP, DDR2, and Collagen I, a known fibroblast marker in lung [1] (Figure 5 and quantified in Table 2). In the lung, 17.5\% of total cells were found to express Collagen $\mathrm{I}^{+}$. In addition, analysis of paraffin sections revealed $3.4 \%$ of $\mathrm{EGFP}^{+}$cells in the lung expressed DDR2 and Collagen I (representative cell indicated by ${ }^{*}$ in Figure 5). Of the EGFP ${ }^{+}$cells, $16.9 \%$ coexpressed EGFP and DDR2 (representative cell indicated by the closed arrow in Figure 5, quantification in Table 2). Analysis of lung sections from nonirradiated control animals showed $\mathrm{CD} 5^{+} / \mathrm{DDR} 2^{+}$cells with a fibroblastic morphology, indicating that the presence of HSC-derived lung fibroblasts was not an artifact of the irradiation necessary for bone marrow transplant conditioning (Supplemental Figure 1). Together, these findings demonstrate the presence of cells in the lung derived from the nonadherent fraction of bone marrow with multiple fibroblastic phenotypes.

3.6. HSCs Give Rise to Lung Fibroblasts. As confirmation of the specific HSC origin of lung fibroblasts, mice engrafted with a clonal population derived from a single sorted HSC were generated as described previously [19-21, 25]. Total

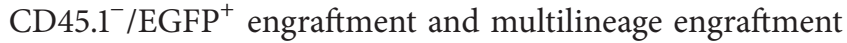
were confirmed (Table 3 ). Lungs were harvested and paraffin embedded and sections were stained for DDR2 and Collagen I to identify fibroblasts derived from the HSC. Numerous $\mathrm{EGFP}^{+}$cells expressing DDR2 (28.8\%) or Collagen I (13.5\%) were identified (Figure 6 and quantified in Table 4), as were $\mathrm{EGFP}^{+}$cells that expressed Collagen I and DDR2 (5.6\%, representative cell indicated by ${ }^{*}$ in Figure 6) confirming an HSC origin of a population of lung fibroblasts. 


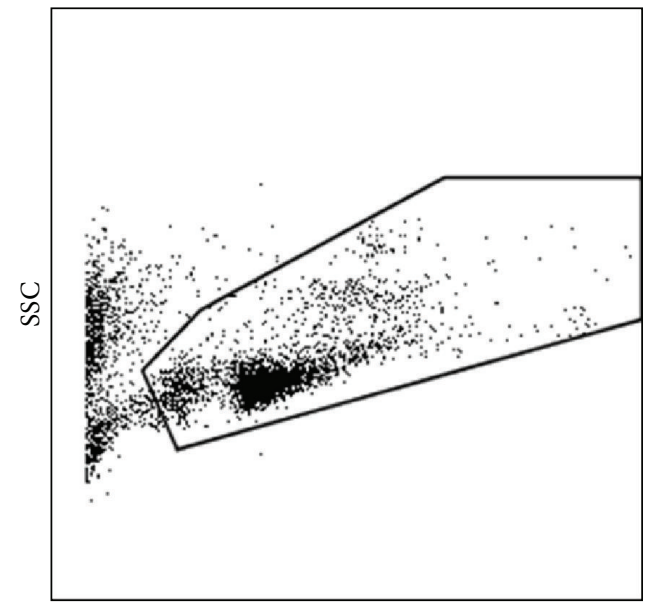

FSC

(a)

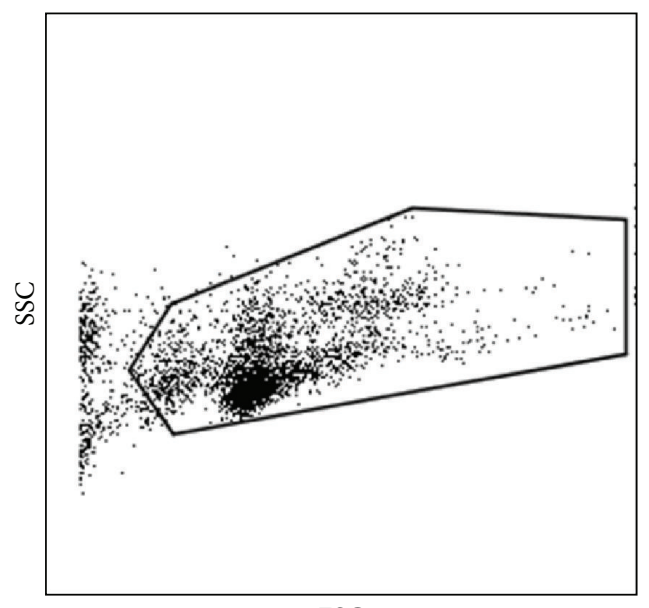

FSC

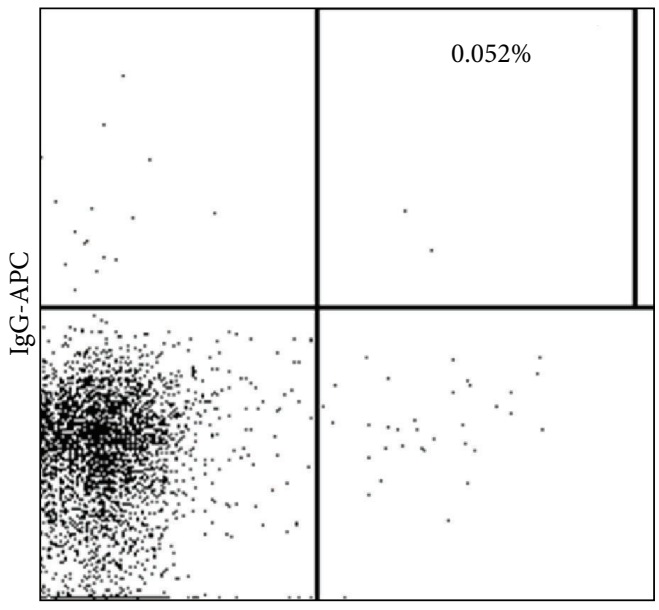

IgG-PE

(b)

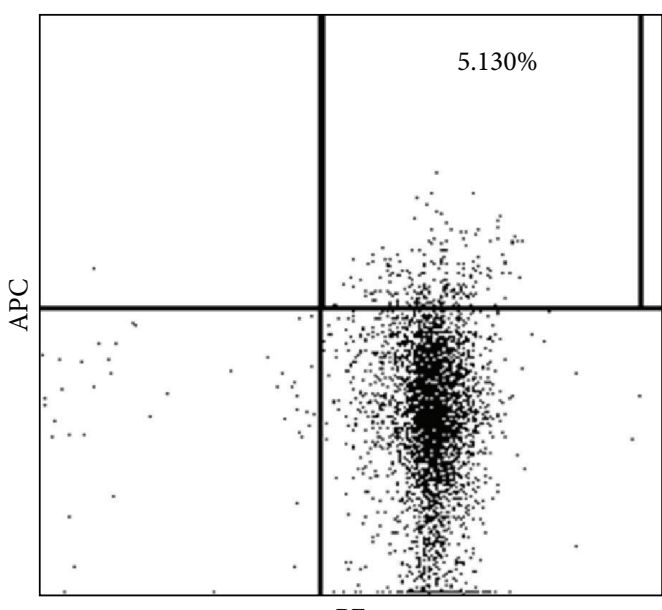

(d)

(c)

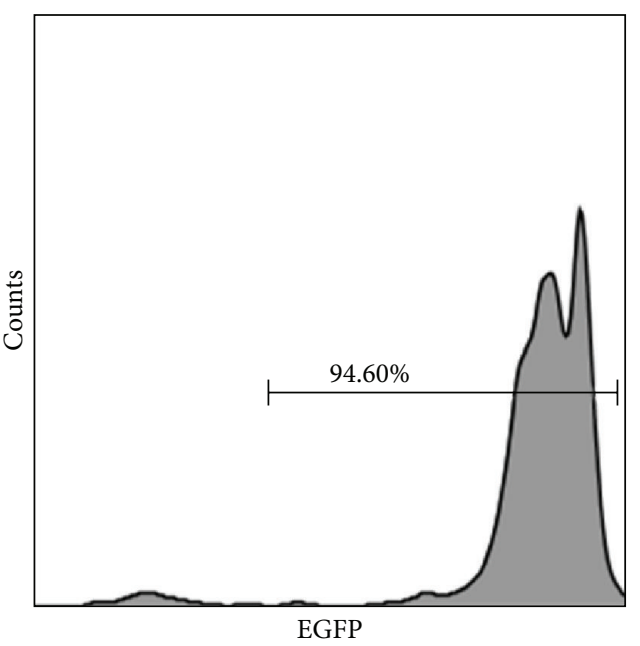

(e)

FIGURE 3: HSC-derived circulating fibroblast precursors are present in the peripheral blood of engrafted mice. Peripheral blood of engrafted nonadherent bone marrow transplanted mice was analyzed for the presence of CFPs. Representative forward scatter and side scatter gate is shown Panel (a) and isotype control is shown in Panel (b). Panels (c)-(e) depict analysis of peripheral blood from a representative animal. Forward and side scatter gate is shown in Panel (c). The population expressing CD45 (PE) and DDR2 (APC) is shown in Panel (d) (upper right quadrant). Analysis of EGFP expression of gated CD $45^{+} / \mathrm{DDR} 2^{+}$population from Panel (d) is shown in Panel (e) (94.6\%). 
DIC

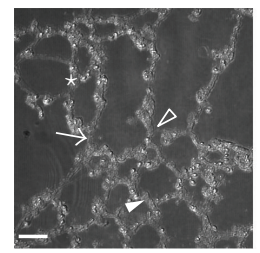

(a)

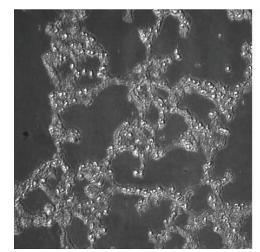

(h)
$\mathrm{HO}$

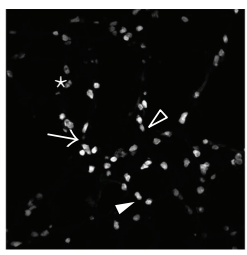

(b)

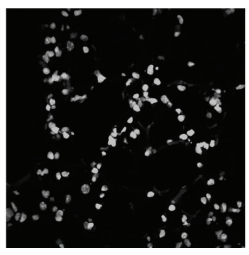

(i)
GFP

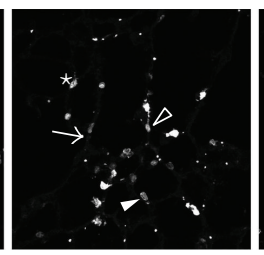

(c)

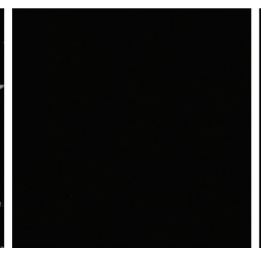

(j)
CD45

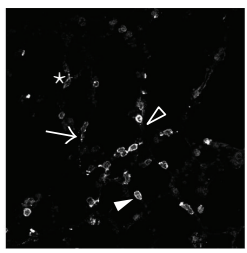

(d)

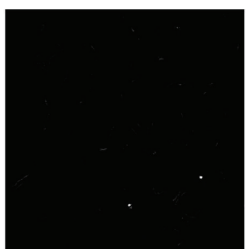

(k)
DDR2

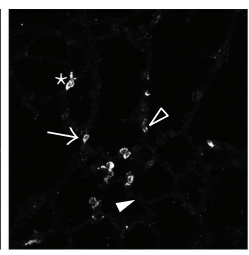

(e)

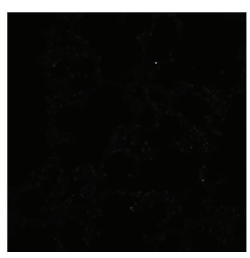

(1)
Merged

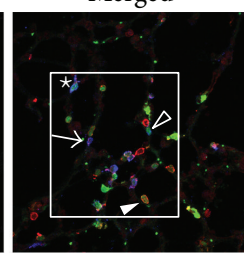

(f)

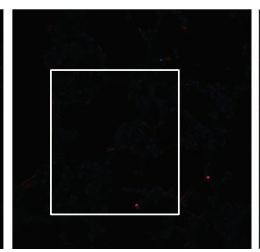

(m)

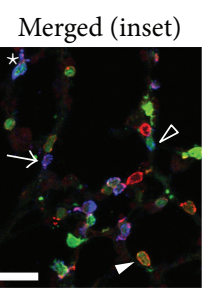

(g)

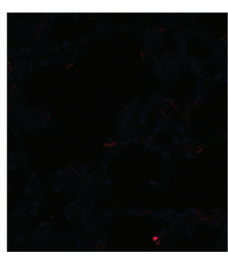

(n)

FIGURE 4: $\mathrm{EGFP}^{+}$CFPs are present in the lungs of nonadherent transplant engrafted mice. Differential interference contrast (DIC), Hoechst nuclear stain (HO), GFP, CD45, and DDR2 antibody stain are shown from a representative lung section from an engrafted animal in Panels (a)-(e), respectively. Panel (f) shows merged image of GFP (green), CD45 (red), and DDR2 (blue) staining. A representative $\mathrm{GFP}^{+} / \mathrm{CD} 45^{+} / \mathrm{DDR}^{+}$cell is indicated by ${ }^{*}$; a representative $\mathrm{GFP}^{+} / \mathrm{CD} 45^{+}$cell is indicated by a solid arrow head; a representative $\mathrm{GFP}^{+} / \mathrm{DDR} 2^{+}$cell is indicated by an open arrow head; and a representative CD45 $5^{+} \mathrm{DDR} 2^{+}$cell is indicated by an arrow. Panel (g) shows higher magnification of inset (boxed area) in Panel (f) with * indicating a GFP ${ }^{+} / \mathrm{CD}^{*} 5^{+} / \mathrm{DDR} 2^{+}$expressing cell. Panels (h) -(n) depict images of secondary only controls. Bar $=25 \mu \mathrm{M}$.

DIC

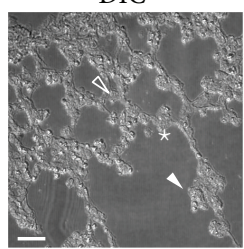

(a)

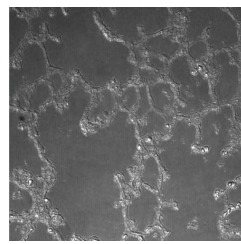

(h)
$\mathrm{HO}$

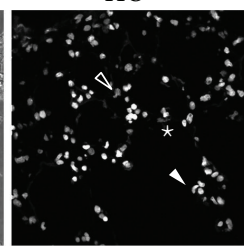

(b)

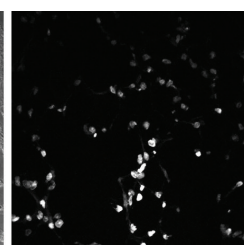

(i)

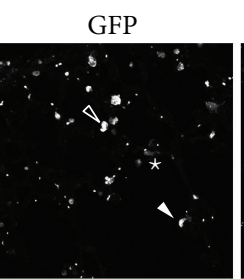

(c)

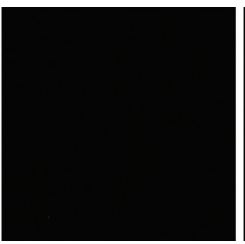

(j)
COL I

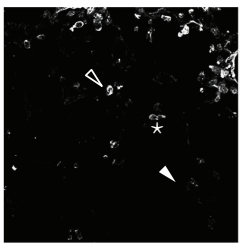

(d)

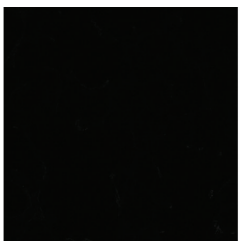

(k)

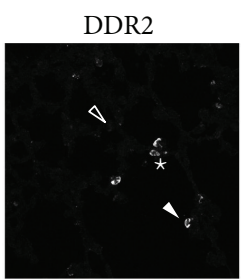

(e)

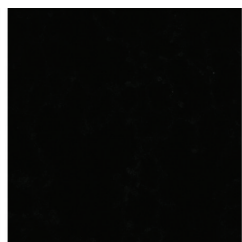

(l)

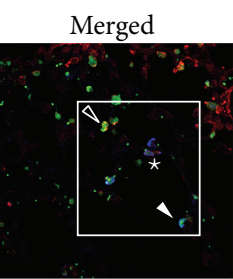

(f)

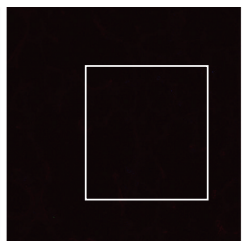

(m)

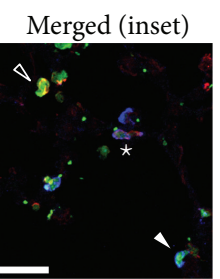

(g)

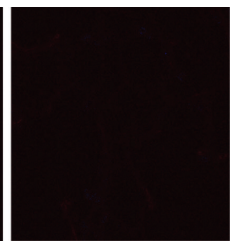

(n)

FIGURE 5: $\mathrm{EGFP}^{+}$lung fibroblasts are present in the lungs of nonadherent transplant engrafted mice. Differential interference contrast (DIC), Hoechst nuclear stain (HO), GFP, Collagen I, and DDR2 antibody stain are shown from a representative lung section from an engrafted animal in Panels (a)-(e), respectively. Panel (f) shows merged image of GFP (green), Collagen I (red), and DDR2 (blue) staining. A representative $\mathrm{GFP}^{+} /$Collagen I $/ \mathrm{DDR}^{+}$cell is indicated by ${ }^{*}$; a representative $\mathrm{GFP}^{+} /$Collagen $\mathrm{I}^{+}$cell is indicated by an open arrow head; a representative $\mathrm{GFP}^{+} / \mathrm{DDR}^{+}$cell is indicated by a solid arrow head. Panel (g) shows higher magnification of inset (boxed area) in Panel (f) with * indicating a $\mathrm{GFP}^{+} / \mathrm{CD} 45^{+} / \mathrm{DDR}^{+}$expressing cell. Panels (h)-(n) depict images of secondary only controls. Bar $=25 \mu \mathrm{M}$.

TABLE 4: HSCs give rise to lung fibroblasts.

\begin{tabular}{lcccc}
\hline & EGFP & EGFP & EGFP & EGFP \\
& & Col I/DDR2 & Col I & $13.5 \%$ \\
DDR2 & $28.8 \%$ \\
Clonal cell transplant & $21.1 \%$ & $5.6 \%$ & $(9.1 \%-23.1 \%)$ & $(20.0 \%-42.3 \%)$ \\
\hline
\end{tabular}

Average percentage in each phenotype is indicated in top row; bottom row gives range of percentages of each phenotype. 
DIC

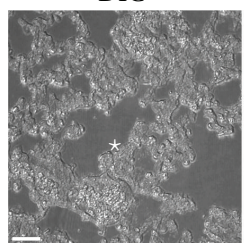

(a)

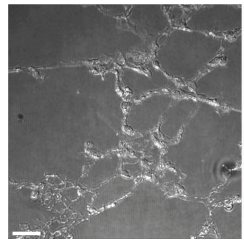

(h)
$\mathrm{HO}$

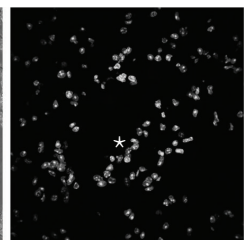

(b)

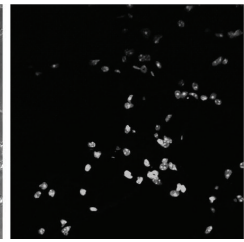

(i)
GFP

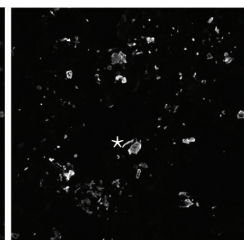

(c)

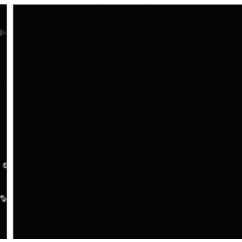

(j)
COL I

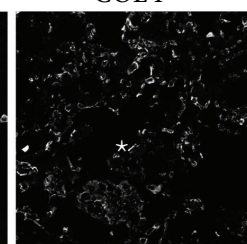

(d)

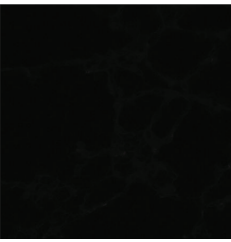

(k)
DDR2

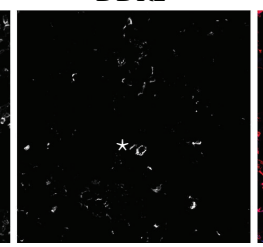

(e)

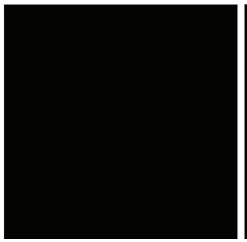

(1)

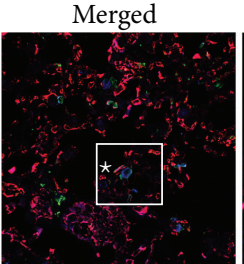

(f)

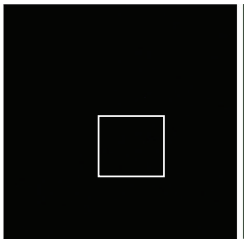

(m)

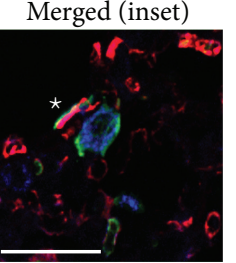

(g)

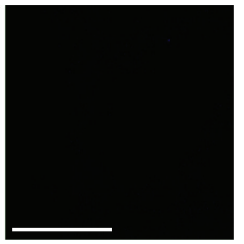

(n)

FIGURE 6: Hematopoietic stem cells give rise to lung fibroblasts in vivo. Differential interference contrast (DIC), Hoechst nuclear stain (HO), EGFP, Collagen I, and DDR2 antibody stain are shown in Panels (a)-(e), respectively, from a representative section of lung tissue from a clonally engrafted mouse. Panel (f) shows merged image of GFP (green), Collagen I (red), and DDR2 (blue) staining. Panel (g) shows higher magnification of inset (boxed area) in Panel (f) with * indicating a GFP/Collagen I/DDR2 expressing cell. Panels (h) -(n) depict images from secondary only staining controls.

\section{Discussion}

Bone marrow stem cell populations have been shown to give rise to fibroblasts in multiple tissues in normal and disease states and our previous studies demonstrate an HSC origin for fibroblasts $[15,16,18,21,35]$ and their precursors $[19,20]$. To our knowledge, no direct lineage tracing studies have previously been performed examining the origin of lung fibroblasts in vivo. In the present study, we add to our previous findings of HSC plasticity by demonstrating that HSCs give rise to a functional lung fibroblast population and show their transition through a circulating fibroblast precursor to a mature lung fibroblast. It should be noted that, due to the turnover rate of lung fibroblasts in nondisease state [36], the fraction of HSC-derived fibroblastic cells observed herein in transplanted animals is likely an underrepresentation of the total HSC-derived lung fibroblast population. The presence of $\mathrm{EGFP}^{+} / \mathrm{CD} 45^{+} / \mathrm{DDR}^{+}$cells in both the blood and lung tissue of engrafted mice suggests that CFPs leave the circulation, enter the lung (with a newly arriving cell retaining the CFP phenotype [20]), and incorporate into the lung tissue. Immunofluorescent characterization of $\mathrm{EGFP}^{+}$HSC-derived cells in the lung tissues revealed the presence of cells with multiple phenotypes. The observation of HSC-derived CD $45^{+} / \mathrm{DDR} 2^{+}$cells (CFPs) as well as HSCderived $\mathrm{CD}_{4} 5^{-}$cells that expressed DDR2 ${ }^{+}$and/or Collagen $\mathrm{I}^{+}$cells suggests a cell in transition. This phenotype is in line with our previous studies that have demonstrated the in vitro transition of bone marrow from an immature phenotype to a fibroblastic phenotype with gradual loss of CD45 expression and gain of DDR2 expression and Collagen I expression [19]. Interestingly, we also observed multiple phenotypes with respect to DDR2 and Collagen I expression in lung fibroblasts, including $\mathrm{EGFP}^{+} / \mathrm{DDR} 2^{-} /$Collagen $\mathrm{I}^{+}$,
$\mathrm{EGFP}^{+} / \mathrm{DDR}^{+} /$Collagen $\mathrm{I}^{-}$, and $\mathrm{EGFP}^{+} / \mathrm{DDR}^{+} /$Collagen $\mathrm{I}^{+}$, suggesting heterogeneity of the HSC-derived lung fibroblast population. Given that DDR2 can serve as a matrix sensing Collagen receptor [37-39], it is possible that the heterogeneous expression of Collagen I and DDR2 is reflective of the function of these cells in steady state.

While the mechanisms regulating the participation, incorporation, and phenotype of HSC-derived cells in the lung remain to be determined, our data suggest that the HSC is a significant and continual contributor to the lung fibroblast population and may have a potential role in disease. Our previous studies in solid tumor have shown that a single HSC can give rise to a significant portion of stromal fibroblasts in disease state [20,21], suggesting that the HSCderived population of lung fibroblasts may indeed increase with disease ([36] and reviewed in [40]). The plasticity of the HSC and presence of circulating intermediates suggest that both the HSC and CFP may be novel and exciting targets for the therapeutic treatment of lung pathologies. Particularly relevant here, the circulating fibroblast precursor population introduces the potential to target this novel HSCderived precursor prior to its incorporation as mature lung fibroblasts. While fibrocytes have been implicated to have a role in lung diseases, they represent only a small portion of circulating leukocytes $(0.1-0.5 \%)$ [41]. The relative size of this population brings into question the potential for this population to be the sole source of recruited fibroblast precursors/fibroblasts in disease such as pulmonary fibrosis. Our data suggests that targeting the CFP may affect a larger proportion of cells capable of giving rise to lung fibroblasts. Further studies of the role of HSC-derived cells in vivo, factors regulating their recruitment and fate, and the ability to be targeted in disease models, are necessary to determine the full contribution of the HSC to lung pathophysiology. 


\section{Ethical Approval}

Research was conducted in strict accordance with guidelines set by the US Public Health Service Policy on Humane Care and Use of Laboratory Animals and the Veterans Affairs Medical Center (VAMC) Institutional Animal Care and Use Committee (IACUC), approved by the Ralph H. Johnson VAMC IACUC, Charleston, SC, under protocol \#534, VA AWA-A3137-01, expiration 12-31-2017. All efforts were made to minimize suffering in animal studies.

\section{Conflict of Interests}

The authors declare that there is no conflict of interests regarding the publication of this paper.

\section{Acknowledgments}

This work was supported by a VA merit awarded to Amanda C. LaRue (BX-12-011). The authors thank the staff of the Radiation Oncology Department of the Medical University of South Carolina in irradiation of mice, and the animal care staff of the Ralph H. Johnson VAMC. They also acknowledge the Hollings Cancer Center Flow Cytometry Core P30 CA138313.

\section{References}

[1] N. Hashimoto, H. Jin, T. Liu, S. W. Chensue, and S. H. Phan, "Bone marrow-derived progenitor cells in pulmonary fibrosis," The Journal of Clinical Investigation, vol. 113, no. 2, pp. 243-252, 2004.

[2] M. W. Epperly, H. Guo, J. E. Gretton, and J. S. Greenberger, "Bone marrow origin of myofibroblasts in irradiation pulmonary fibrosis," The American Journal of Respiratory Cell and Molecular Biology, vol. 29, no. 2, pp. 213-224, 2003.

[3] R. Bucala, L. A. Spiegel, J. Chesney, M. Hogan, and A. Cerami, "Circulating fibrocytes define a new leukocyte subpopulation that mediates tissue repair," Molecular Medicine, vol. 1, no. 1, pp. 71-81, 1994.

[4] M. Schmidt, G. Sun, M. A. Stacey, L. Mori, and S. Mattoli, "Identification of circulating fibrocytes as precursors of bronchial myofibroblasts in asthma," The Journal of Immunology, vol. 171, no. 1, pp. 380-389, 2003.

[5] V. N. Lama and S. H. Phan, "The extrapulmonary origin of fibroblasts: stem/progenitor cells and beyond," Proceedings of the American Thoracic Society, vol. 3, no. 4, pp. 373-376, 2006.

[6] H. Xia, V. Bodempudi, A. Benyumov et al., "Identification of a cell-of-origin for fibroblasts comprising the fibrotic reticulum in idiopathic pulmonary fibrosis," American Journal of Pathology, vol. 184, no. 5, pp. 1369-1383, 2014.

[7] B. C. Willis, R. M. DuBois, and Z. Borok, "Epithelial origin of myofibroblasts during fibrosis in the lung," Proceedings of the American Thoracic Society, vol. 3, no. 4, pp. 377-382, 2006.

[8] N. Hashimoto, S. H. Phan, K. Imaizumi et al., "Endothelialmesenchymal transition in bleomycin-induced pulmonary fibrosis," American Journal of Respiratory Cell and Molecular Biology, vol. 43, no. 2, pp. 161-172, 2010.

[9] C. Hung, G. Linn, Y.-H. Chow et al., "Role of lung pericytes and resident fibroblasts in the pathogenesis of pulmonary fibrosis,"
American Journal of Respiratory and Critical Care Medicine, vol. 188, no. 7, pp. 820-830, 2013.

[10] N. Hutchison, C. Fligny, and J. S. Duffield, "Resident mesenchymal cells and fibrosis," Biochimica et Biophysica Acta, vol. 1832, no. 7, pp. 962-971, 2013.

[11] M. Ogawa, A. C. Larue, P. M. Watson, and D. K. Watson, "Hematopoietic stem cell origin of mesenchymal cells: opportunity for novel therapeutic approaches," International Journal of Hematology, vol. 91, no. 3, pp. 353-359, 2010.

[12] M. Ogawa, A. C. LaRue, P. M. Watson, and D. K. Watson, "Hematopoietic stem cell origin of connective tissues," Experimental Hematology, vol. 38, no. 7, pp. 540-547, 2010.

[13] I. Catacchio, S. Berardi, A. Reale et al., "Evidence for bone marrow adult stem cell plasticity: properties, molecular mechanisms, negative aspects, and clinical applications of hematopoietic and mesenchymal stem cells transdifferentiation," Stem Cells International, vol. 2013, Article ID 589139, 11 pages, 2013.

[14] K. Shirai, Y. Sera, W. Bulkeley et al., "Hematopoietic stem cell origin of human fibroblasts: cell culture studies of female recipients of gender-mismatched stem cell transplantation and patients with chronic myelogenous leukemia," Experimental Hematology, vol. 37, no. 12, pp. 1464-1471, 2009.

[15] R. P. Visconti, Y. Ebihara, A. C. LaRue et al., "An in vivo analysis of hematopoietic stem cell potential: hematopoietic origin of cardiac valve interstitial cells," Circulation Research, vol. 98, no. 5, pp. 690-696, 2006.

[16] H. Lang, Y. Ebihara, R. A. Schmiedt et al., "Contribution of bone marrow hematopoietic stem cells to adult mouse inner ear: mesenchymal cells and fibrocytes," Journal of Comparative Neurology, vol. 496, no. 2, pp. 187-201, 2006.

[17] F. Ishikawa, C. J. Drake, S. Yang et al., “Transplanted human cord blood cells give rise to hepatocytes in engrafted mice," Annals of the New York Academy of Sciences, vol. 996, pp. 174-185, 2003.

[18] M. Masuya, C. J. Drake, P. A. Fleming et al., "Hematopoietic origin of glomerular mesangial cells," Blood, vol. 101, no. 6, pp. 2215-2218, 2003.

[19] Y. Ebihara, M. Masuya, A. C. Larue et al., "Hematopoietic origins of fibroblasts: II. In vitro studies of fibroblasts, CFUF, and fibrocytes," Experimental Hematology, vol. 34, no. 2, pp. 219-229, 2006.

[20] R. S. Abangan Jr., C. R. Williams, M. Mehrotra, J. D. Duncan, and A. C. LaRue, "MCP1 directs trafficking of hematopoietic stem cell-derived fibroblast precursors in solid tumor," The American Journal of Pathology, vol. 176, no. 4, pp. 1914-1926, 2010.

[21] A. C. LaRue, M. Masuya, Y. Ebihara et al., "Hematopoietic origins of fibroblasts: I. In vivo studies of fibroblasts associated with solid tumors," Experimental Hematology, vol. 34, no. 2, pp. 208-218, 2006.

[22] M. Ogawa, A. C. LaRue, and C. J. Drake, "Hematopoietic origin of fibroblasts/myofibroblasts: its pathophysiologic implications," Blood, vol. 108, no. 9, pp. 2893-2896, 2006.

[23] L. T. McDonald and A. C. LaRue, "Hematopoietic stem cell derived carcinoma-associated fibroblasts: a novel origin," International Journal of Clinical and Experimental Pathology, vol. 5, no. 9, pp. 863-873, 2012.

[24] T. Nakanishi, A. Kuroiwa, S. Yamada et al., "Fish analysis of 142 EGFP transgene integration sites into the mouse genome," Genomics, vol. 80, no. 6, pp. 564-574, 2002.

[25] M. Mehrotra, C. R. Williams, M. Ogawa, and A. C. LaRue, "Hematopoietic stem cells give rise to osteo-chondrogenic 
cells," Blood Cells, Molecules, and Diseases, vol. 50, no. 1, pp. 4149, 2013.

[26] M. Osawa, K.-I. Hanada, H. Hamada, and H. Nakauchi, "Longterm lymphohematopoietic reconstitution by a single CD34low/negative hematopoietic stem cell," Science, vol. 273, no. 5272, pp. 242-245, 1996.

[27] S. Fricke, C. Fricke, C. Oelkrug et al., "Characterization of murine non-adherent bone marrow cells leading to recovery of endogenous hematopoiesis," Cellular and Molecular Life Sciences, vol. 67, no. 23, pp. 4095-4106, 2010.

[28] J. S. Lebkowski, M. A. McNally, S. Finch et al., "Enrichment of murine hematopoietic stem cells. Reconstitution of syngeneic and haplotype-mismatched mice," Transplantation, vol. 50, no. 6, pp. 1019-1027, 1990.

[29] F. Kiefer, E. F. Wagner, and G. Keller, "Fractionation of mouse bone marrow by adherence separates primitive hematopoietic stem cells from in vitro colony-forming cells and spleen colonyforming cells," Blood, vol. 78, no. 10, pp. 2577-2582, 1991.

[30] A. J. Friedenstein, U. F. Deriglasova, N. N. Kulagina et al., "Precursors for fibroblasts in different populations of hematopoietic cells as detected by the in vitro colony assay method," Experimental Hematology, vol. 2, no. 2, pp. 83-92, 1974.

[31] M. F. Pittenger, A. M. Mackay, S. C. Beck et al., "Multilineage potential of adult human mesenchymal stem cells," Science, vol. 284, no. 5411, pp. 143-147, 1999.

[32] Z. L. Zhang, J. Tong, R. N. Lu, A. M. Scutt, D. Goltzman, and D. S. Miao, "Therapeutic potential of non-adherent BM-derived mesenchymal stem cells in tissue regeneration," Bone Marrow Transplantation, vol. 43, no. 1, pp. 69-81, 2009.

[33] S. Otsuru, P. L. Gordon, K. Shimono et al., "Transplanted bone marrow mononuclear cells and MSCs impart clinical benefit to children with osteogenesis imperfecta through different mechanisms," Blood, vol. 120, no. 9, pp. 1933-1941, 2012.

[34] S. Fricke, M. Ackermann, A. Stolzing et al., "Allogeneic nonadherent bone marrow cells facilitate hematopoietic recovery but do not lead to allogeneic engraftment," PLoS ONE, vol. 4, no. 7, Article ID e6157, 2009.

[35] D. C. Hess, T. Abe, W. D. Hill et al., "Hematopoietic origin of microglial and perivascular cells in brain," Experimental Neurology, vol. 186, no. 2, pp. 134-144, 2004.

[36] J. G. Clark, K. M. Kostal, and B. A. Marino, "Modulation of collagen production following bleomycin-induced pulmonary fibrosis in hamsters. Presence of a factor in lung that increases fibroblast prostaglandin E2 and cAMP and suppresses fibroblast proliferation and collagen production," The Journal of Biological Chemistry, vol. 257, no. 14, pp. 8098-8105, 1982.

[37] P. A. Ruiz and G. Jarai, "Discoidin domain receptors regulate the migration of primary human lung fibroblasts through collagen matrices," Fibrogenesis and Tissue Repair, vol. 5, no. 1, article 3, 2012.

[38] D. Kim, E. You, N. Y. Min, K.-H. Lee, H. K. Kim, and S. Rhee, "Discoidin domain receptor 2 regulates the adhesion of fibroblasts to $3 \mathrm{D}$ collagen matrices," International Journal of Molecular Medicine, vol. 31, no. 5, pp. 1113-1118, 2013.

[39] E. Olaso, J.-P. Labrador, L. Wang et al., "Discoidin domain receptor 2 regulates fibroblast proliferation and migration through the extracellular matrix in association with transcriptional activation of matrix metalloproteinase-2," The Journal of Biological Chemistry, vol. 277, no. 5, pp. 3606-3613, 2002.

[40] D. L. Clarke, A. M. Carruthers, T. Mustelin, and L. A. Murray, "Matrix regulation of idiopathic pulmonary fibrosis: the role of enzymes," Fibrogenesis and Tissue Repair, vol. 6, article 20, 2013.
[41] R. Abe, S. C. Donnelly, T. Peng, R. Bucala, and C. N. Metz, "Peripheral blood fibrocytes: differentiation pathway and migration to wound sites," The Journal of Immunology, vol. 166, no. 12, pp. 7556-7562, 2001. 

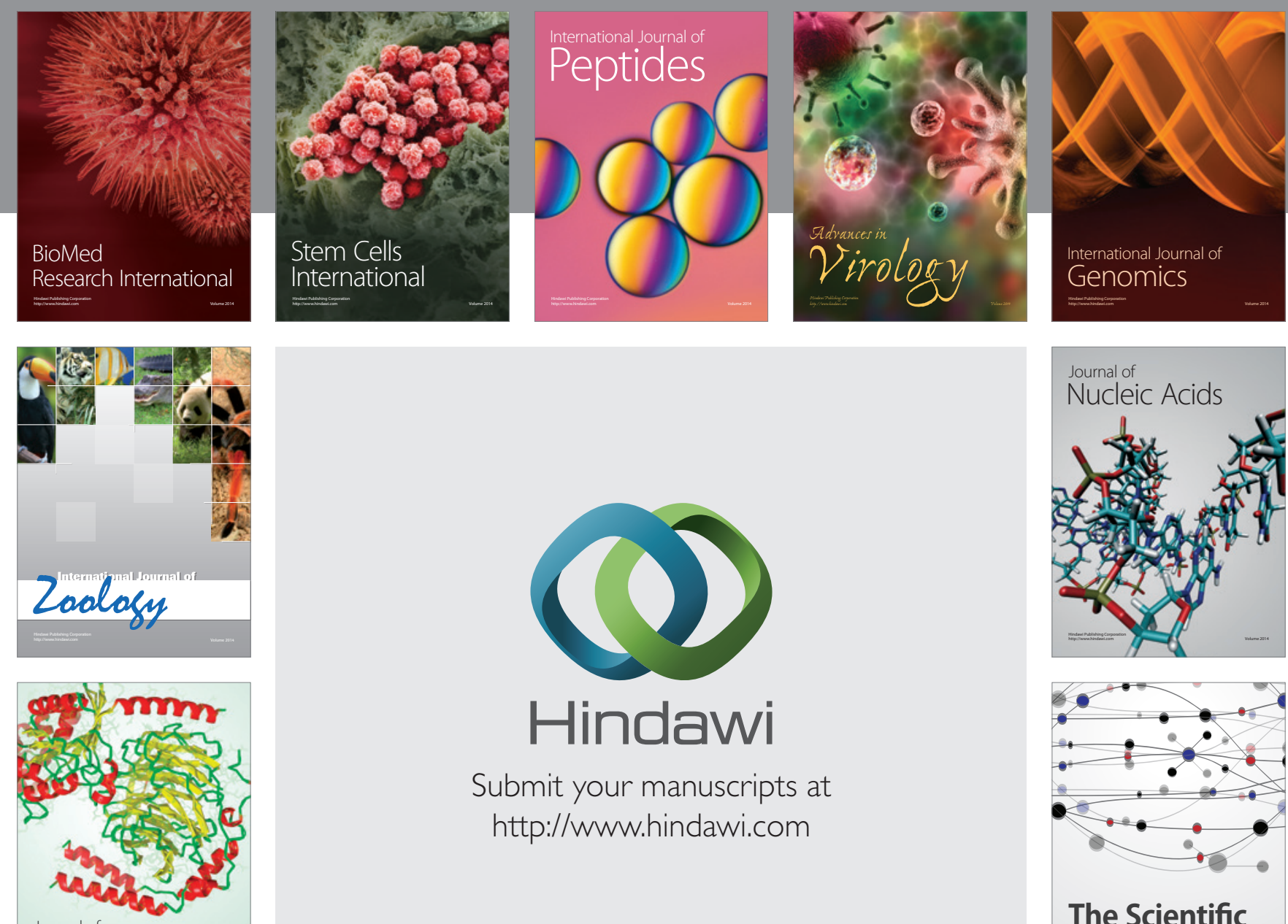

Submit your manuscripts at

http://www.hindawi.com

Journal of
Signal Transduction
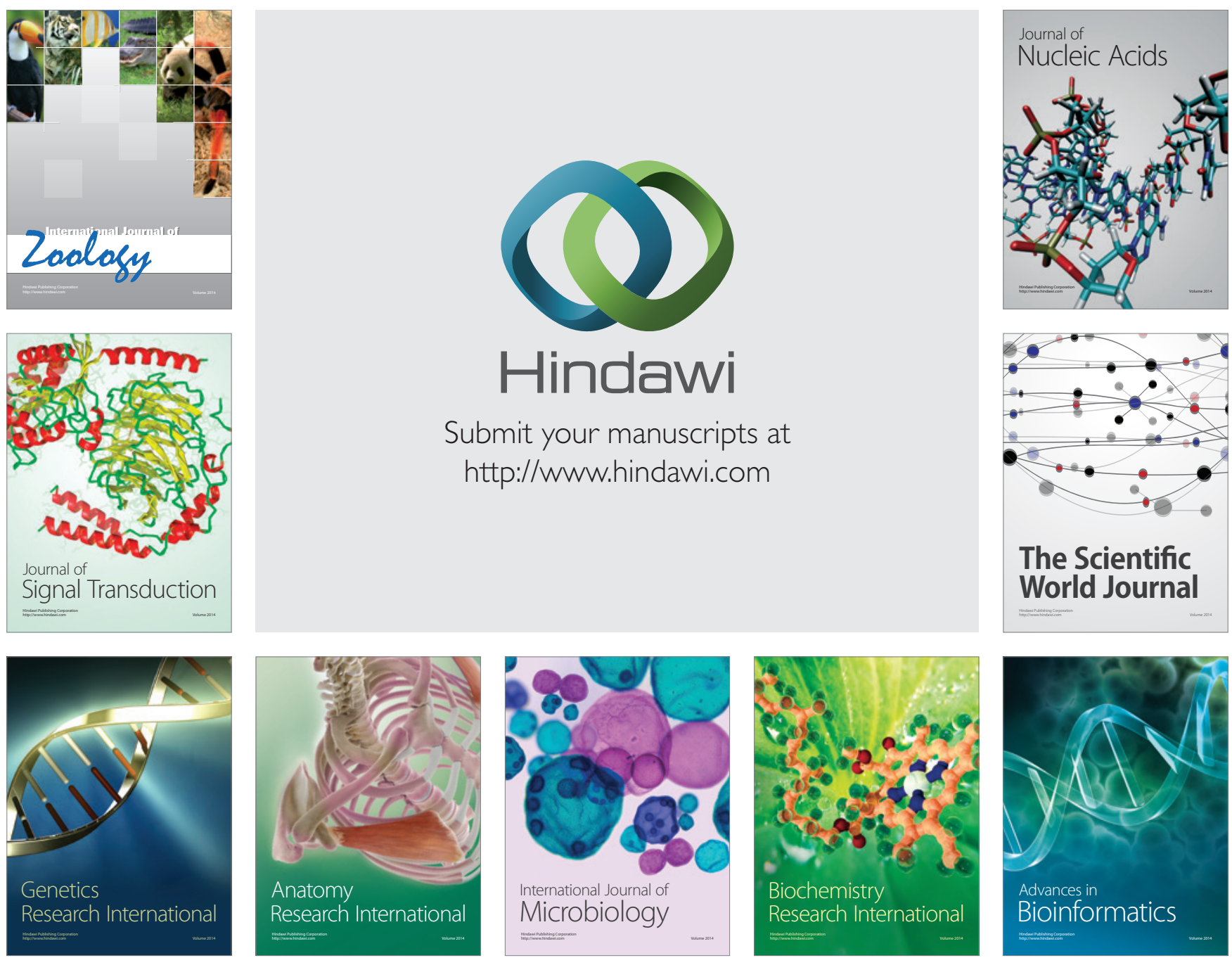

The Scientific World Journal
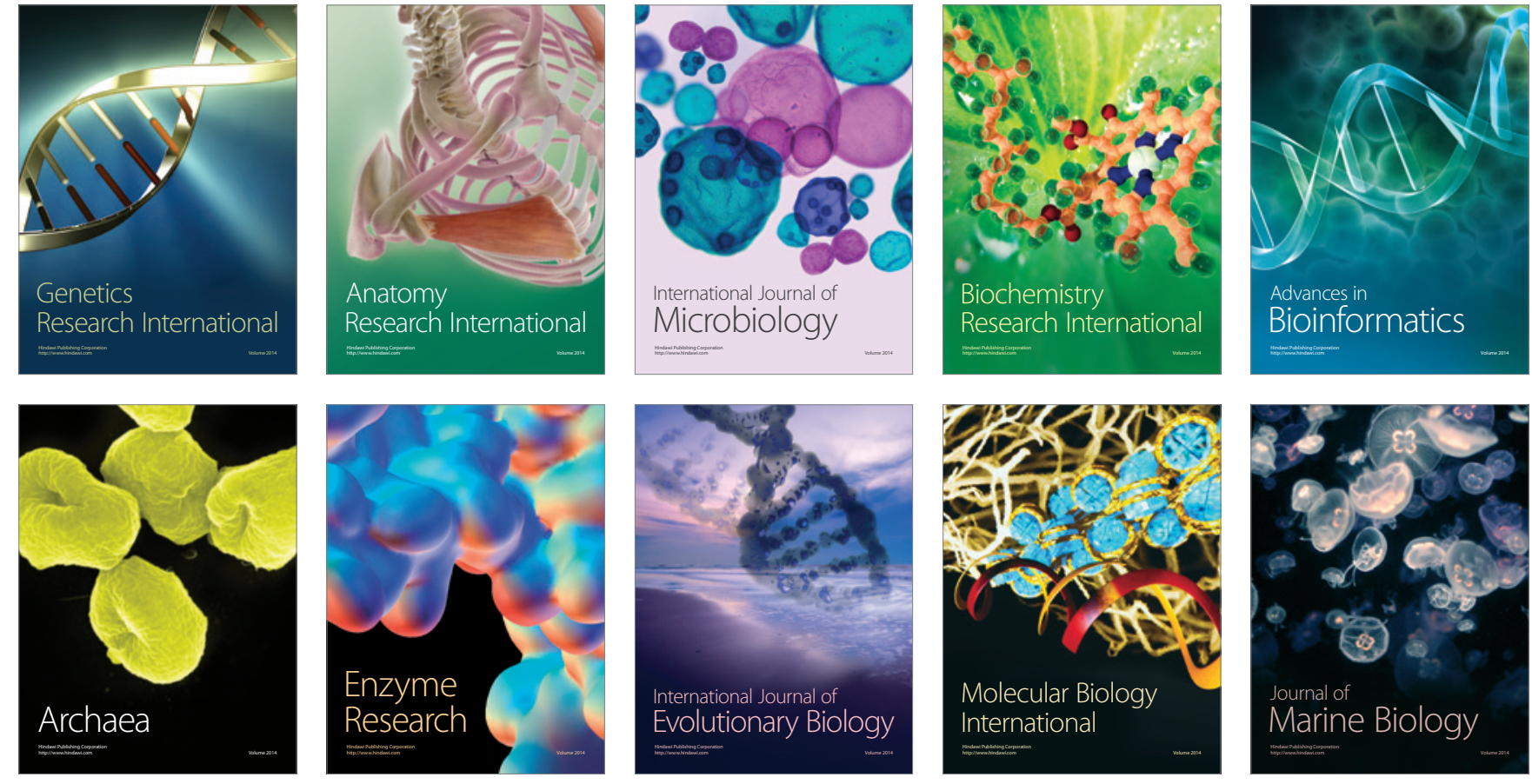